\title{
Triangular model integrating clinical teaching and assessment
}

This article was published in the following Dove Press journal:

Advances in Medical Education and Practice

4 March 2014

Number of times this article has been viewed

\author{
Adel Abdelaziz ${ }^{1,2}$ \\ Emad Koshak ${ }^{3}$ \\ 'Medical Education Development \\ Unit, Faculty of Medicine, Al Baha \\ University, Al Baha, Saudi Arabia; \\ ${ }^{2}$ Medical Education Department, \\ Faculty of Medicine, Suez Canal \\ University, Egypt; ${ }^{3}$ Dean and Internal \\ Medicine Department, Faculty of \\ Medicine, Al Baha University, Al Baha, \\ Saudi Arabia
}

\begin{abstract}
Structuring clinical teaching is a challenge facing medical education curriculum designers. A variety of instructional methods on different domains of learning are indicated to accommodate different learning styles. Conventional methods of clinical teaching, like training in ambulatory care settings, are prone to the factor of coincidence in having varieties of patient presentations. Accordingly, alternative methods of instruction are indicated to compensate for the deficiencies of these conventional methods. This paper presents an initiative that can be used to design a checklist as a blueprint to guide appropriate selection and implementation of teaching/learning and assessment methods in each of the educational courses and modules based on educational objectives. Three categories of instructional methods were identified, and within each a variety of methods were included. These categories are classroom-type settings, health services-based settings, and community service-based settings. Such categories have framed our triangular model of clinical teaching and assessment.
\end{abstract}

Keywords: curriculum development, teaching, learning, assessment, apprenticeship, community-based settings, health service-based settings

\section{Introduction}

Doctors traditionally studied their craft in an apprenticeship model within hospitals. In the 21 st century medical education context, apprenticeship means "getting students involved in service as much as current regulations permit." Currently, there is a trend of medical schools to move toward more structured and far-reaching horizons when providing clinical experience. ${ }^{2}$

In order to increase students' exposure to clinical experience, many schools have started to develop teaching in ambulatory care that includes outpatients and primary care and to mobilize students outside the boundaries of colleges and health service outlets to a wide range of community settings. ${ }^{3}$

Teaching within these settings has several disadvantages, ie, it may not include experience of all skills identified in the objectives, it requires direct observation by faculty for optimal use and it needs perceptors and students preparation and training. ${ }^{4}$

In view of these disadvantages, a diversity of conventional and alternative teaching methods and settings is indicated. A structured model that can encompass these instructional methods within different settings in a balanced manner can help to overcome the above problems. The purpose of this work was to identify a way of circumventing the shortcomings of conventional instructional methods of clinical teaching through development of a structured and multifaceted teaching model for clinical
Correspondence: Adel Abdelaziz Medical Education Development Unit, Faculty of Medicine, Al Baha University PO Box 1988, Al Baha, Saudi Arabia

Tel +96 6555242678

Fax +96677247272

Email doctoradel5@yahoo.com 


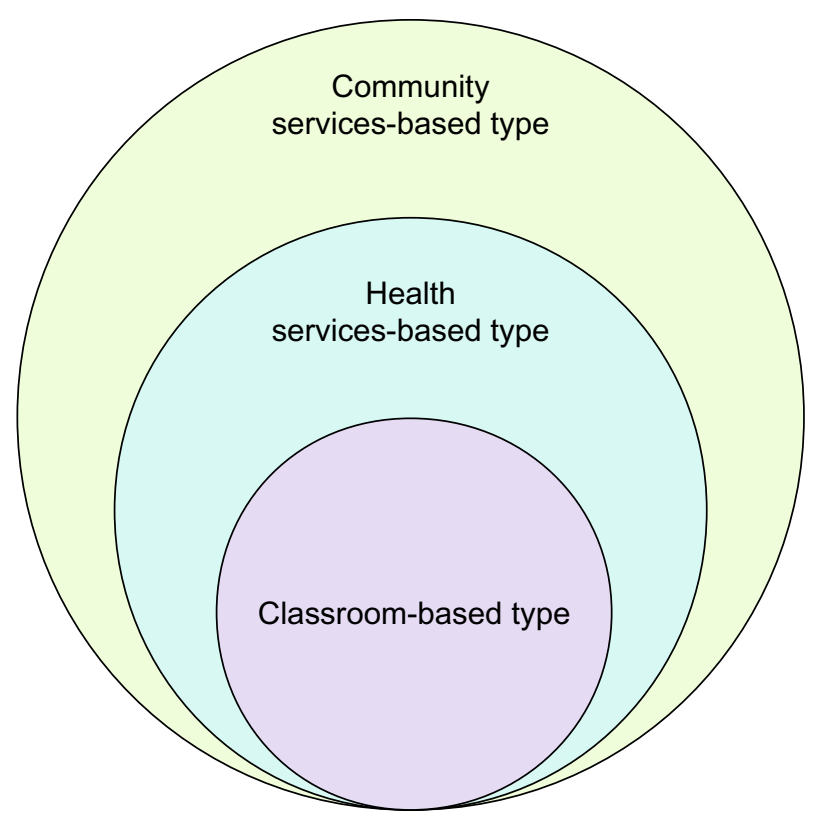

Figure I Three angles of the triangular model of clinical teaching/learning and assessment.

education at the Faculty of Medicine, Al Baha University (FMBU), that could be generalized in local Saudi or regional Arab contexts.

\section{Materials and methods}

During the planning phase of curriculum development at FMBU, a newly founded community-based medical school in the south west of Saudi Arabia, a committee was formed to develop a structured teaching/learning model. This committee has two main functions: first, to identify features of a model that can integrate learning objectives from one side and methods of teaching/learning and assessment from the other, and second, to undertake the needs assessment relevant for implementation and evaluation of this model.

To characterize the target model and assess the requirements for implementation and program evaluation, we
Table I Identified instructional methods under each category of the triangular model of clinical teaching/learning and assessment

\begin{tabular}{ll}
\hline Categories of TMCTA & $\begin{array}{l}\text { Subcategories (methods } \\
\text { of instruction) }\end{array}$ \\
\hline I Classroom-type settings & Ordinary classrooms \\
& - Tutorials \\
- Seminars & - Problem-based learning \\
& - Directed self learning \\
& - Microteaching \\
- Interactive lectures & - Practical laboratories of basic \\
& medical sciences \\
Skills laboratory: depends on \\
utilization of \\
- Manikins \\
- High fidelity simulations \\
- Simulated patients \\
- One-on-one training \\
- Video demonstrations \\
- Role playing \\
- Bedside teaching \\
- Shadowing \\
- Training in outpatient clinics \\
- Training in emergency settings \\
- Training in diagnostic units \\
- Training in rehabilitative units \\
- Training in primary health care \\
settings & - Settings \\
- Site visits \\
settings
\end{tabular}

Abbreviation: TMCTA, triangular model of clinical teaching/learning and assessment.

reviewed the relevant literature, consulted medical education experts in the region, benchmarked international, regional, and local medical education curricula, and canvased the views and perspectives of medical students, faculty staff, and

Table 2 Blueprint matrix for the triangular model integrating clinical teaching/learning and assessment

\begin{tabular}{|c|c|c|c|c|c|c|c|c|c|c|c|c|c|c|c|c|c|}
\hline \multicolumn{18}{|c|}{ Course/module title:....... Code:........ Credit units: ....... Course coordinator: ......... } \\
\hline \multirow{2}{*}{ 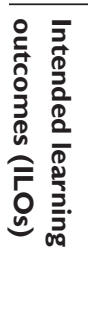 } & \multicolumn{7}{|c|}{$\begin{array}{l}\text { I. Classroom-type } \\
\text { settings }\end{array}$} & \multicolumn{5}{|c|}{$\begin{array}{l}\text { II. Health service- } \\
\text { based settings }\end{array}$} & \multicolumn{4}{|c|}{$\begin{array}{l}\text { III. Community- } \\
\text { based settings }\end{array}$} & \multirow{2}{*}{ 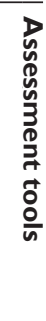 } \\
\hline & 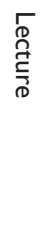 & $\begin{array}{l}-1 \\
\frac{c}{\overline{0}} \\
\frac{0}{2} \\
\frac{\hat{N}}{n}\end{array}$ & 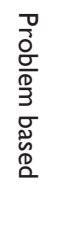 & 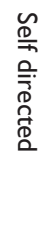 & . & 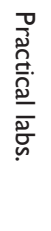 & $\begin{array}{l}\frac{n}{0} \\
\hat{\overline{\bar{n}}} \\
\underline{0} \\
\dot{0}\end{array}$ & 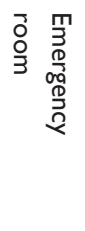 & 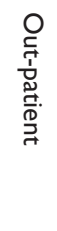 & 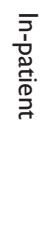 & 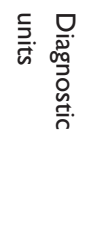 & 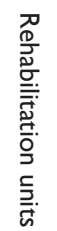 & 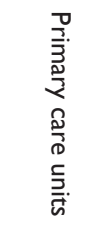 & 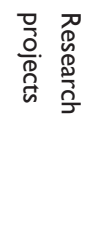 & 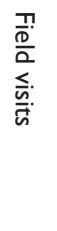 & 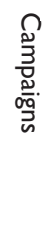 & \\
\hline Total & & & & & & & & & & & & & & & & & \\
\hline
\end{tabular}


community representatives. Students' views were explored using a self-administered questionnaire while the views of faculty and community representatives were explored by focus groups.

After characterization of the teaching/learning and assessment model and before its implementation in the clerkship phase, the developed model was implemented on a pilot basis via a clinical theme of "community-based primary health care" integrated longitudinally in the first 3 years of the undergraduate curriculum at FMBU. After 3 years of adopting this teaching/learning and assessment model, inferences regarding program evaluation were collected and interpreted.

\section{Results}

These research efforts have resulted in our being able to define characteristics of the target model. These characteristics are: reliance on learning objectives through the three domains of learning, potential to prepare students in a safe learning environment prior to contact with real patients, provision of a diversity of educational settings to adapt different learning styles, subject to monitoring and evaluation, allowing for timely and continuous assessment of student performance, in harmony with and applicable to the community-based curriculum of FMBU, and ensuring optimal utilization of all the resources available at the school and beyond.

After characterization of the model, a variety of instructional and assessment methods have been identified that can be used to build up the target model. The instructional methods identified were then categorized according to where they can be conducted under three main headings, ie, classroom-type settings, health services-based settings, and community service-based settings. Such categories have framed our triangular model of clinical teaching and assessment (TMCTA, Figure 1).

The categories and subcategories of instructional methods identified were then tabulated in a blueprint matrix that can guide selection among these methods according to the learning objectives of each study course or module (Tables 1 and 2). Assessment methods are then selected according to the learning objective and teaching method (Table 1). Using this blueprint matrix has helped to achieve balanced inclusion of different teaching/learning and assessment methods within the TMCTA focused on the clinical theme of "community-oriented primary health care" studied in the basic sciences phase.

Needs assessment has identified the financial resources, human resources, tools, and equipment necessary for implementation and evaluation of the TMCTA. Allocation of financial resources, tools, and equipment for establishing a clinical skills laboratory and equipping classrooms was not a problem. There was a shortage of faculty staff members essential for teaching, facilitation, and preceptorship. Faculty members from Egypt and Sudan have been engaged for this purpose. Faculty development program and community awareness campaigns were identified as prerequisites and initiated before implementation of the model.

For program evaluation purposes, student and faculty questionnaires were developed and used to assess satisfaction with the TMCTA. In addition to the questionnaires, inferences made from student assessment were utilized to evaluate the model. The evaluation revealed that the TMCTA is affordable and applicable in the context of the FMBU as well as the local Saudi community. Financial resources would not be an issue in the FMBU or other Saudi medical schools if this model was adopted. Resistance on the part of staff and students and lack of cooperation in the local community were seen as the main obstacles to teaching within the community settings.

\section{Discussion}

Adopting a variety of teaching/learning methods in clinical teaching is a necessity and not a luxury. This is underscored by the old saying of Osler, ie, "To study the phenomena of a disease without books is to sail an uncharted sea, whilst to study books without patients is not to go to sea at all." Based on that principle, the three identified categories of instructional settings were subcategorized on a scale of different but complementary methods. On a pilot basis, these methods were entered in the blueprint matrix according to their relevance to the objectives of an educational course

To benefit the steering effect of assessment, ${ }^{6}$ a variety of timely and ongoing student assessment tools were incorporated on the basis of their relevance to both educational objectives and methods of instruction within each of the categories. These assessment tools include a portfolio, logbook, evaluation of research projects, case studies, and 360-degree assessment. These methods can be used for continuous assessment that adds to the summative assessment of students in a certain module or for formative assessment and feedback.

After 3 years of implementing this teaching/learning and assessment model, the feedback from students, faculty, and community representatives has been very encouraging. In spite of being a consuming exercise in terms of human and financial resources, the TMCTA is feasible and affordable, given the resources allocated for higher education in Saudi Arabia in general and the small number of students per cohort at FMBU in particular. 


\section{Conclusion}

TMCTA is affordable and feasible within the local Saudi medical education context. The developed blueprint can be utilized to guide selection of teaching/learning and assessment methods in medical schools throughout the region, taking into account the disparity in resources between one country and another. Involvement of students, faculty, and community representatives in the development and evaluation of TMCTA ensures a high level of utility. Diversification and integration of assessment and instructional methods help with accommodation of the learning styles of different students and ensure validity of assessment. Simultaneous distribution of students to various instructional activities provides opportunities for teaching in small groups, which is considered important in contemporary medical education.

What characterizes and makes the TMCTA innovative is its structured nature guided by the blueprint matrix and the increased time and weight given to balancing community- based learning situations with more conventional and wellknown educational settings.

\section{Disclosure}

The authors report no conflicts of interest in this work.

\section{References}

1. Dornan T. Osler, Flexner, apprenticeship and the new medical education. J R Soc Med. 2005;98:91-95.

2. Hartley S, Gill D, Carter F, Walters K, Bryant P. Teaching Medical Students in Primary and Secondary Care: A Resource Book. Oxford, UK: Oxford University Press; 2003.

3. Malley P, Kroenke K, Ritter J, Dy N, Pangaro L. What learners and teachers value most in ambulatory educational encounters: a prospective, qualitative study. Acad Med. 1999;74:186-191.

4. Wehrli G, Nyquist JG. Teaching strategies methodologies; advantages, disadvantages, cautions and keys to success. Creating an educational curriculum for learners at any level. AABB Conference 2003.

5. Salam A, Siraj H, Mohamad N, Das S, Yousuf Y. Bedside teaching in undergraduate medical education: issues, strategies, and new models for better preparation of new generation doctors. Iran J Med Sci. 2011;36: $1-6$.

6. Amin Z, Chong YS, Khoo HE. Towards better practices in medical student assessment. Ann Acad Med Singapore. 2005;34:471-472.
Advances in Medical Education and Practice

\section{Publish your work in this journal}

Advances in Medical Education and Practice is an international, peerreviewed, open access journal that aims to present and publish research on Medical Education covering medical, dental, nursing and allied health care professional education. The journal covers undergraduate education, postgraduate training and continuing medical education

\section{Dovepress}

including emerging trends and innovative models linking education, research, and health care services. The manuscript management system is completely online and includes a very quick and fair peer-review system. Visit http://www.dovepress.com/testimonials.php to read real quotes from published authors. 